\title{
Education's Stake In The Optics Industry
}

\author{
Jack Gaskill
}

Jack D. Gaskill, "Education's Stake In The Optics Industry," Proc. SPIE 0978, 1988 Intl Conf on Education in Optics, (27 April 1989); doi:

$10.1117 / 12.948598$

Event: 32nd Annual International Technical Symposium on Optical and United States 


\author{
Education's stake in the optics industry \\ Jack D. Gaskill \\ University of Arizona, Optical Sciences Center \\ Tucson, Arizona 85721
}

\title{
ABSTRACT
}

The stake that those involved in optics education programs have in the optics industry is discussed, and suggestions are made regarding desired outcomes that will help ensure the survival of these programs. Suggestions are also made for actions that should be taken to attain the desired outcomes.

\section{INTRODUCTION}

In this paper, the term optics is used in a generic sense and includes the disciplines of optical physics, optical sciences and optical engineering. At the present time, there are a number of academic units at universities around the country that have educational programs in optics at either the undergraduate level or the graduate level (or both). Although a few of the graduates of these programs end up in academic positions, most are hired by industrial corporations or governmental agencies. As long as the graduates of the optics programs meet the optics-related needs of industry and government better than the graduates of more traditional programs, such as electrical engineering or physics, these optics programs will continue to exist. If, for some reason, the electrical engineering and physics graduates become better suited to the needs of industry and government, the optics programs will tend to fade away. Consequently, "education's stake in the optics industry" would seem to be a matter of survival.

\section{WHAT SHOULD BE DONE?}

Some individuals would argue that, in enlightened self interest, universities and academic units involved in optics programs should take an active role in charting the future course of the optics industry. Others might say that nature should simply be allowed to take its course, and that optics programs should exist as long as there is funding for them and a need for their graduates; if the sources of funding dry up, or the need diminishes, some or all of these educational programs should be allowed to simply vanish. It is my belief that those of us involved in optics education ought to attempt the former, but not totally rule out the latter. We can have an impact on the future of the optics industry, but we shouldn't insist on training the optical equivalents of buggy-whip makers.

So how do we help steer the future of the industry? One very important thing we can do is to educate our students instead of 
merely training them; they should not be trained to solve the problems of yesterday or today, but must be given the tools that will allow them to attack the problems of tomorrow. Does this kind of statement argue against, the existence of individuals from universities and industry, highly specialized programs in optics, applied optics, optical engineering, etc.? Yes, to some extent-but not entirely. After all, such highly specialized programs as electrical engineering and mechanical engineering are very common, very successful and greatly needed. On the other hand, we must guard against the tendency to overspecialize, as urged by other individuals from industry, and make certain that our curriculum is as up to date and as forward looking as possible.

\section{HOW CAN WE DO IT?}

First, we need to enlist greater support from industry. This statement may elicit cries of anguish from some of my industry friends who think that their companies are already being bled to death--and we still want more? My response to them is that there is some evidence that the amount of governmental funding for optics programs--particularly those programs with a classical or engineering emphasis--is diminishing, and it is imperative that we increase our industrial base if we are to survive. Additionally, if industry really does have a need for our graduates, it is also in their self interest to support us to an even greater extent than they are now.

It will be difficult to obtain increased industrial funding because, in many corporations, optics doesn't seem to get the respect that it should. The CEO's, board members and other upperlevel managers are most often from backgrounds other than optics, and their perception of the importance of optics to the overall health of their businesses may be aberrated. Even though large parts of their businesses may be optics related or optics dependent, optics may appear to be relatively unimportant and the personnel working in this area tend to be treated as industrial Rodney Dangerfields.

Another thing that should be done is to increase the interaction between universities and industrial firms/governmental laboratories. It is common for university faculty to take sabbatical leaves, but often these sabbaticals are spent at other universities and in the same type of atmosphere found at their own universities. Although many faculty involved in university optics programs are not typical ivory tower dwellers, it could be very valuable for some of them to spend at least part of a sabbatical in industry by helping to delay the onset of academic arteriosclerosis. It could also prove to be very worthwhile if more companies allowed their employees to spend a sort of reverse sabbatical leave at a university. Such individuals might receive adjunct appointments, participate in teaching, act as consultants on research projects, serve as members of curriculum committees, supervise thesis projects of students, etc. Other activities that 
should be started or expanded are joint university/industry research programs, co-op programs, fellowship programs and equipment donations, summer employment for faculty and students, industrial presentations at university colloquia and faculty talks to industrial audiences, etc.

Such stepped up interactions between universities and industry cannot be achieved without increased short-term costs, but these may be offset by the long-term benefits. There are tremendous "bottom line" pressures that tend to force both universities and corporations to focus on short-term solutions and goals, but such actions are often quite myopic and lead to severe difficulties later on. Both academia and industry must constantly force themselves to look as far down the road as possible.

\section{CONCLUSIONS}

Is there optical radiation at the portal of the underground passageway? Yes, there is. As more and more graduates of optics programs attain high-level management positions in industry and government, more and more appreciation of the importance of optics will find its way into these organizations. And as the importance of optics is appreciated more and more, the cooperative activities mentioned previously will get more attention and support. In addition, such awareness can be enhanced by the constant but diplomatic efforts of both university and industry employees to make certain that those in decision-making positions get the message.

Because those involved in optics education and those employed in the optics industry have stakes in each other, hard work and cooperation will help to ensure the survival of both groups. "United we stand--divided we fall." 